\title{
Mentalizing techniques used by psychodynamic therapists working with children and early adolescents
}

\author{
Pablo Muñoz Specht, DClinPsy \\ Karin Ensink, PhD \\ Lina Normandin, $\mathrm{PhD}$ \\ Nick Midgley, PhD
}

The aim of this study was to identify, categorize, and develop a conceptual frame of mentalization-based interventions used by experienced child and adolescent psychodynamic therapists. Two experienced therapists selected 14 sessions that represented their work during the first year of treatment. Sessions were transcribed and segmented to identify interactional units for coding. QDA Miner software was used to facilitate data analysis. A systematic qualitative, inductiveldeductive approach was followed starting from categories identified in the literature, but also including newly emerging categories and interventions. Seven sessions were double coded to stabilize the coding tree and a "member check" was completed where therapists rated their own transcripts. A total of 24 mentalization-based techniques were identified, including 17 additional techniques. A conceptual framework organizing all observed mentalization-based interventions is proposed. The findings of this study provide a framework for studying techniques that may enhance the capacity to mentalize, and that could be features of therapentic practice across a range of modalities of psychotherapy. (Bulletin of the Menninger Clinic, 80[4], 281-315)

Pablo Muñoz Specht, Karin Ensink, and Lina Normandin are at the Université Laval, École de psychologie, Québec, Canada. Nick Midgley is at the Anna Freud Centre and in the Research Department of Clinical, Educational and Health Psychology, University College London, Gower Street, London, UK.

Correspondence may be sent to Karin Ensink, Université Laval, École de psychologie, Pavillon Félix-Antoine-Savard, FAS-1426, Québec, Canada G1V 0A6; e-mail: Karin. Ensink@psy.ulaval.ca (Copyright @ 2016 The Menninger Foundation) 
Mentalizing as conceptualized by Fonagy, Gergely, Jurist, and Target (2002) can be understood as an imaginative mental activity involved in understanding others and predicting their behaviors in terms of their internal subjective motivations, and seeing oneself and the impact of one's behaviors from the outside. Mentalizing, although falling under the general rubric of social cognition, and overlapping with concepts such as Theory of Mind (ToM) and emotional understanding, is considered specifically relevant in the context of close attachment relationships where a more nuanced understanding of others, oneselfand the impact of one's behaviors on others is likely particularly important for adaptive functioning. Among psychotherapists, there is a rapidly growing interest not only in mentalization-based treatments (MBT), but also in thinking about how psychotherapy generally, regardless of orientation, addresses and facilitates the capacity to mentalize.

In recent years, there has been a proliferation of MBT adaptations for a range of adult psychological difficulties, and there is evidence of the efficacy of MBT for adults and adolescents with borderline personality disorders (Bateman \& Fonagy, 2012; Fonagy et al., 2014; Rossouw \& Fonagy, 2012). Furthermore, studies that have attempted to explore mechanisms of change have produced preliminary evidence that both MBT and psychodynamic therapy facilitate mentalizing, which may help to explain the observed improvements in symptoms and personality functioning. For example, there is evidence that MBT for parents with substance dependence develop mentalizing about themselves and their relationships with their children (Suchman, DeCoste, Leigh, \& Borelli, 2010) and that psychodynamic treatments, such as transference-focused psychotherapy, improve mentalizing about past attachment relationships (Clarkin, Levy, Lenzenweger, \& Kernberg, 2007). Allen, Fonagy, and Bateman (2008) suggest that enhancing mentalizing may be a common process factor inherent to all effective treatments. Further empirical investigation is needed, but there is preliminary evidence that promoting mentalizing may be a common feature of both psychodynamic and cognitive-behavioral child treatments (Goodman, Midgley, \& Schneider, 2016) as well as MBT and play therapy (Goodman, Reed, \& Athey-Lloyd, 2015). 
Psychotherapy from a mentalization perspective

Furthermore, expanding evidence regarding the relationship between child and adult psychopathology, social cognition, and mentalizing has contributed to the development of cognitive-behavioral therapies aimed, for example, at facilitating emotional understanding in the context of anxiety disorders (SouthamGerow \& Kendall, 2000) or limiting rumination in the context of depression (Hankin, Wetter, Cheely, \& Oppenheimer, 2008).

Relative to research on MBT with adults, research on mentalization-based interventions for adolescents and especially children is lagging behind, despite research showing that child and adolescent psychopathology may be associated with difficulties in mentalizing specifically (Ensink, Bégin, Normandin, \& Fonagy, 2016; Sharp, Croudace, \& Goodyer, 2007; Taubner \& Curth, 2013) and social-cognitive deficits more generally (Reyna, Chapman, Dougherty, \& Confrey, 2012; Steinberg, 2008). From a developmental perspective, there is evidence that socialcognitive capacities such as ToM and emotional understanding, as well as mentalization, develop in the context of children's attachment relationships with adults interested in their subjective experience, who treat them as someone with a mind, and where they have the opportunity to learn about their own minds and those of others through conversations where mental states and emotional experience are talked about and explained. While there is evidence that even very young children are sensitive to the reactions of others, the ability to articulate their own feelings and consider the internal motivations behind the behaviors of others emerges more slowly as language skills develop (Fonagy \& Target, 2000). There is evidence that around the age of 8 , mentalization takes on a more adult character and children begin to be able to think about themselves and their relationships with attachment figures (Ensink et al., 2015; Wellman \& Lagattuta, 2000).

Some children have few opportunities to develop mentalizing capacities, either because their parents themselves may have difficulty mentalizing or because the parents have mental health problems or overwhelming social problems that prevent them from engaging with their children in ways that will help the children develop these capacities. As a result, some children may experience pervasive mentalization deficits. Subsequently, failures in mentalizing appear to increase vulnerability to develop- 
Muñoz Specht et al.

ing depressive symptoms and externalizing behavior difficulties (Ensink et al., 2016). Alternatively, children who face challenging life events or who have particularly difficult temperaments involving sensitivity and aggressive emotional reactivity likely require additional help to develop a capacity to mentalize that could enable them to integrate these temperamental factors. For example, mentalization regarding trauma appears to be particularly important for adaptive functioning for individuals who have experienced childhood abuse and neglect (Berthelot et al., 2015; Ensink et al., 2015). In sum, emerging evidence is consistent with clinical observations that many children and adolescents need help from therapists to develop mentalization and socio-cognitive capacities.

In the 1980s, Fonagy started elaborating a developmental model in which psychopathology is linked to failures in the developing understanding of minds, emotions, and others, from infancy onwards (Fonagy, Steele, Steele, Moran, \& Higgitt, 1991). Subsequently, he observed that psychotherapy with children included a dimension of what Anna Freud referred to as development help (Midgley, 2012), a form of psychological support in developing basic mentalizing around psychological reactions. This type of focus is also present in other psychotherapy approaches, notably Paulina Kernberg's adaptation of the object-relations approach (Kernberg \& Chazan, 1991) in which the therapist provides information that may help the child to understand his or her own reactions much like a good parent might think about the child's reactions and explain by placing them in the context of common human reactions to certain emotion-eliciting interpersonal events or intrapersonal conflicts. In addition, child therapy may enhance reflective processes through opportunities to play and through work in the transference (Fonagy \& Target, 2000).

Subsequently, Ensink and Normandin (2011) elaborated a mentalization-based therapy for sexually abused children, and Zevalkink, Verheugt-Pleiter, and Fonagy (2012) reinterpreted psychoanalytic psychotherapy from a mentalization perspective. Furthermore, a recent qualitative study using the Child Psychotherapy Q-Set suggests that MBT and psychodynamic play therapy approaches share key features (Goodman et al., 2016). Given that play is a precursor of mentalization (Fonagy 
Psychotherapy from a mentalization perspective

\& Target, 1996; Tessier, Normandin, Ensink, \& Fonagy, 2016), play therapy may be particularly important for facilitating mentalizing. Fonagy (2000) suggests that the therapist can facilitate mentalizing by commenting on the mental content of the play characters, the child's behavior, or play. The therapist can identify mental states underlying the child's behavior or play, or verbalize the wishes or intentions of the play characters, significant others in the child's life such as parents, or reflect on the uniqueness of the child's mental world. However, the focus of play therapy is to help the child to elaborate his or her subjective experience and restore healthy self-development. Therefore, enhancing mentalization may be a by-product of play therapy, whereas in MBT the focus may be more explicitly on mentalization.

To date few studies have focused explicitly on identifying techniques used by child therapists that address mentalization. Identifying techniques aimed at developing the capacity to mentalize in child psychotherapy-whether the treatment is mentalization based, cognitive-behavioral, or psychodynamic-is an important first step to eventually being able to compare the use of such techniques across different kinds of therapies and examine which techniques appear to be the most effective for different types of problems. The aim of this pilot study was therefore to identify, categorize, and conceptualize interventions aimed at promoting mentalization used by psychodynamic child psychotherapists employing an integration of mentalization-based approaches (Ensink \& Normandin, 2011) and object relations approaches (Kernberg, Weiner, \& Bardenstein, 2000; Normandin, Ensink, Yeomans, \& Kernberg, 2014) with children and early adolescents (aged 8-13 years old).

Method

\section{Participants and procedure}

The participation of two experienced child and adolescent psychotherapists was solicited. The therapists were asked to select work with a child or young adolescent patient aged 8-13. Therapy sessions from 1 year of treatment were videotaped, and the therapists were asked to select five sessions from the beginning, 
Muñoz Specht et al.

middle, and final period of therapy that they considered most representative of their work. These sessions were transcribed verbatim.

The patients were a 10-year-old boy and a 13 -year-old boy. The type of psychopathology was not specified by the researchers, but both of the patients met criteria for oppositional defiant disorder. The 10-year-old boy had comorbid encopresis and attention-deficit hyperactivity disorder (ADHD), as well as symptoms of self-harm. He had a history of trauma, having witnessed his father's death from a heart attack when he was 4 years old. He was placed in a government facility during treatment because his mother was depressed and her devaluing and punitive reactions to his oppositional behaviour contributed to an escalation of aggression. The 13-year-old boy had aggressive outbursts at school and was at risk for being expelled. He also had violent outbursts with his mother, once threatening her with a knife. He oscillated between angry outbursts and resentful, silent withdrawal and refusal to participate in family interaction, suggesting the presence of personality problems.

\section{Data analysis plan}

In view of the exploratory nature and objectives of this pilot study, the "Framework approach" was followed using a combined deductive/inductive analysis (Pope, Ziebland, \& Mays, 2000; Ritchie \& Spencer, 2002). The framework analysis approach reflects the original accounts and observations of the people studied (therefore remaining both "grounded" and inductive), but starts deductively from preset categories (Pope et al., 2000), in this case based on a review of the relevant literature and pilot observations of some of the child therapy sessions. Using PsycNET and EBSCOhost, we identified a total of 10 pertinent manuals, chapters, and published articles referring to mentalization-based intervention for children and adolescents (Ensink \& Normandin, 2011; Fonagy et al., 2014; IngleyCook \& Dobel-Ober, 2013; Laurenssen et al., 2014; Lindqvist, 2013; Midgley \& Vrouva, 2013; Ramires, Schwan, \& Midgley, 2012; Rossouw \& Fonagy, 2012; Terradas \& Achim, 2013; Verheugt-Pleiter \& Zevalkink, 2008). The book chapter "Mentalization-Based Treatment for Adolescents With Border- 
Psychotherapy from a mentalization perspective

line Traits" (Fonagy et al. 2014) describes mentalization-based techniques in detail in order to be used for coding purposes. Although Verheugt-Pleiter and Zevalkink's book describes child psychoanalytic treatment from a mentalization perspective, it was decided not to use it because the mentalization techniques were not sufficiently differentiated from psychoanalytic techniques or described with sufficient clarity for coding purposes. Furthermore, to be coherent with the MBT adult framework, the MBT manual for adults, Mentalizing in Clinical Practice (Allen et al., 2008), was used as a second source. On this basis, seven main MBT techniques were selected as the starting point for coding. They were defined as: (1) supportive and empathic interventions, (2) clarification and elaboration techniques, (3) mentalizing the transference techniques, (4) basic mentalizing techniques, (5) stop, rewind, and explore, (6) transference tracer comments, and (7) interpretative mentalizing. These techniques were organized under a central theme referred as the Mentalizing Stance Principle (MSP). All interactions between the therapist and the patient were coded.

QDA Miner software, version 4 (Provalis Research, Montreal, Canada), was used to facilitate data analysis. Initially, the seven intervention categories were identified on the basis of the literature review. These categories were subsequently adapted based on ideas emerging from the data, with some of them grouped together and others expanded. One preestablished technique, namely stop and rewind, was not observed. Different passages of therapy session transcripts were subsequently associated with the different categories. At the end of this inductive process, 24 interventions or categories were identified and grouped under one general theme and three subthemes. Overall, 969 passages extracted from the therapy sessions were coded.

As recommended by Thomas (2006), different verification strategies were used to contribute to scientific rigor. First, as suggested by Miles and Huberman (1994), different categories were defined in order to facilitate the interpretation of the session transcripts. These descriptions contributed to the standardization of the codification process. New categories were the subject of discussion among the researchers, with four meetings held to discuss the main emerging codes. Second, as recommended by Thomas (2006) to "stabilize" the coding tree, the 
Muñoz Specht et al.

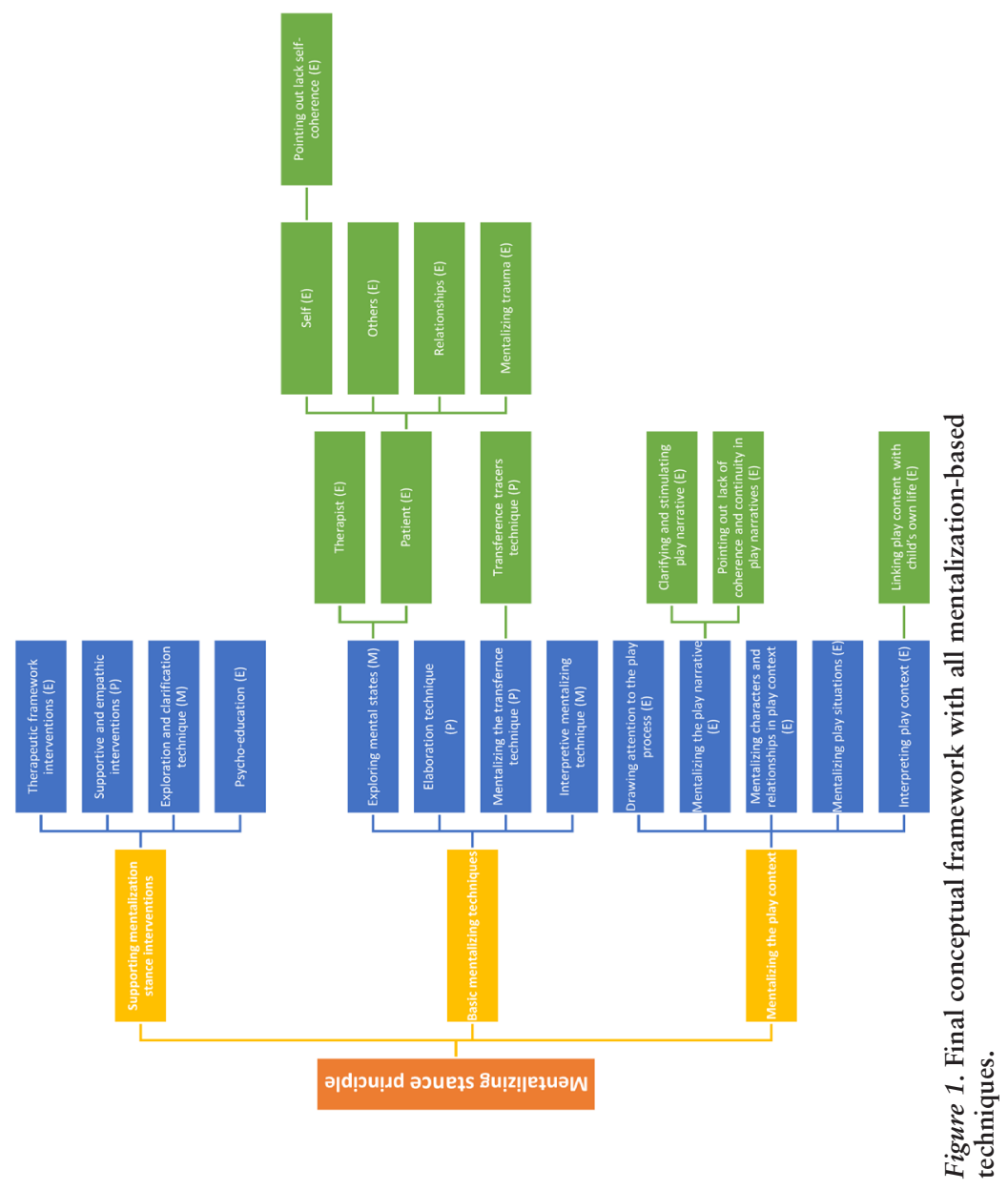


Psychotherapy from a mentalization perspective

clarity of categories was verified. Seven session transcripts were coded by a second rater. Differences were identified and descriptions were clarified. Third, a "member check" was completed with both therapists (Thomas, 2006). They were informed of the research objective and the preliminary categories that had been developed, and they were each asked to review one of their coded therapy sessions to evaluate agreement between therapist coding and researcher coding. The rater and the therapists were in agreement on 90 of 99 passages, and feedback from the therapists confirmed that the categories were clear and comprehensive.

\section{Results}

The final conceptual framework with the 24 mentalizationbased techniques identified in the coding process is illustrated in Figure 1. The figure specifies when the categories were preestablished $(\mathrm{P})$ in the literature; when they were preestablished but modified $(\mathrm{M})$ based on emerging ideas; and when they were emerging from the analysis (E), that is, emerged out of the analysis.

\section{The mentalizing stance principle}

The mentalizing stance principle was the central theme unifying all the techniques and giving coherence to the whole conceptual framework. In general terms, the mentalizing stance principle refers to the therapist's orientation toward the internal world of the patient. Allen et al. (2008) suggest that in order to restore and consolidate the patient's capacity to mentalize, the therapist has to adhere to the mentalizing stance principle for the duration of the treatment.

\section{Supporting mentalizing stance interventions}

During the coding process, it became evident that some interventions used by both therapists were not directly mentalization-focused interventions, but were evidently important for introducing the idea and stimulating the mentalization stance in therapy. They were thus included in the coding tree and categorized and organized under the supporting the mentalizati- 
Muñoz Specht et al.

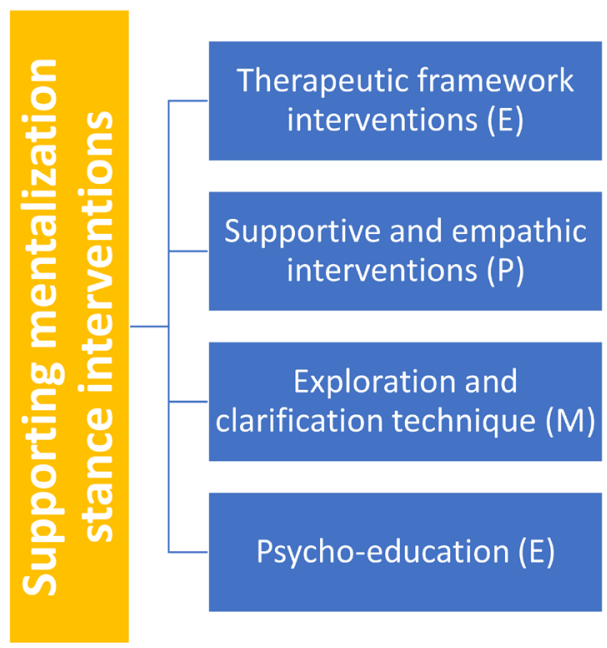

Figure 2. Section 1 of the conceptual framework: supporting mentalization stance interventions.

on stance interventions theme. At the final stage of the coding process, four categories were grouped under this theme. Figure 2 illustrates the conceptual framework of the four mentalization-based techniques that were organized under the supporting mentalizing stance intervention theme.

Therapeutic framework interventions. Therapeutic framework interventions refer to all interventions where the therapist explains, discusses, and explores the therapeutic frame with the patient. Issues such as rules, the work plan, the limits and the engagements of the therapist and the child or the adolescent are addressed. Therapists used this type of intervention in almost all sessions (adolescent therapist, 9 out of 15 sessions; child therapist, 13 out of 13 sessions). This intervention is used to set limits, clarify some therapeutic rules, address trust and confidentiality issues, and establish the conditions to work with the patient and explore the patient's mental state. For example, when the therapist was speaking about how feedback would be given to parents, she said: 
Psychotherapy from a mentalization perspective

Therapist: They have to know a bit what we will do together, what I will conclude (results). But I'll tell you in advance what I will tell them and we will have time, you and me, to discuss it and it won't be about things that we have not discussed together. Other than that, the details of what happens here will stay here....

Supportive and empathic interventions. This intervention is used to facilitate trust that the therapist understands and is "neutrally" on the child's side and to develop the therapeutic alliance. At any stage in the therapy when the patient is emotionally dysregulated and struggling to mentalize, the therapist returns to this empathic stance to attempt to regulate the heightened affective arousal (Fonagy et al., 2014). This intervention is an active process, and active questioning may be used when necessary, with the therapist checking that he or she has understood what the patient has said, validating his or her point of view and being in contact with the patient's emotional state. This type of intervention was used by both therapists in almost all sessions (adolescent therapist, 11/15, and child therapist, 9/13) in line with the observation that an empathic stance is a central component of the mentalizing stance. An example of the therapeutic use of this technique can be observed in the following extract where the adolescent therapist empathically highlights the adolescent's courage in sharing his feelings during an earlier joint session with the patient's parents (rather than resorting to his usual strategy of sullen retreat) when they talked about an embarrassing incident where he was unable to complete a summer camp because he could not fit in and he asked his parents to come and get him after a few days:

Therapist: I found you courageous for being able to explain how you felt in the meeting with your parents ... and for ... tolerating ... that meeting ... staying present. You didn't ... you didn't sink down in your chair, you didn't fall asleep. You took a risk to tell them how you felt, and I had the impression it helped them to understand your reaction and it helped to resolve the situation.

Exploration and clarification technique. This is an active technique where the therapist asks questions with the aim of making sense of the patient's difficulties so that problems become clear and triggers are understood. This technique was 
Muñoz Specht et al.

used by both therapists in the majority of sessions (adolescent therapist, 15/15, and child therapist, 12/13). For the adolescent therapist, this technique was the intervention most frequently used $(28.9 \%)$, and it was the fourth most used intervention for the child therapist $(10.7 \%)$. Here is one of the several passages where the adolescent therapist explores and tries to clarify an interpersonal context presented in therapy:

Therapist: How is it going at home? ...

Adolescent: Fine...

Therapist: Ah, yeah?

Adolescent: [Silence]

Therapist: What is going fine?

Adolescent: Fine... at home?

Therapist: Hmm? What is going well? What do you find that goes well?

Adolescent: Everything. Except my brother.

Therapist: In what way ... do you want to say more?

In this section, the adolescent is then able to clarify with the help of the therapist how he becomes impatient and enraged with his younger brother and acts sadistically toward him. The adolescent is able to share the underlying resentment he feels for having to babysit his brother, which in turn is linked to feeling resentful because his parents spend little time with him so that he feels neglected.

Psychoeducation. This technique is used to provide information to help the children understand normative aspects of their reactions that they may otherwise consider only as bizarre or problematic (e.g., that it is normal to get angry when they are humiliated and want to defend and protect themselves; or that it is not unusual for them to struggle with sexualized behaviors after abuse or to have enjoyed, for example, the attention they got from an abuser, and to feel very guilty about that, and 
Psychotherapy from a mentalization perspective

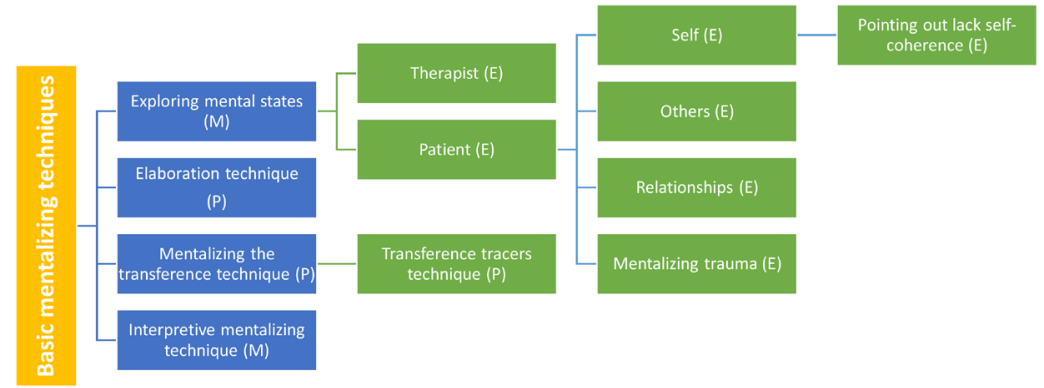

Figure 3. Section 2 of the conceptual framework: basic mentalizing techniques.

to explain that their physiological reaction was not under their control). In fact, the technique is often used to help the children develop an awareness of and recover their thinking about their reactions in a way that helps them understand the normative aspect where they are trying their best to find a solution to a particular problem. Psychoeducation may also be invaluable to help the children develop a way of thinking about an abusing or mentally ill parent and abuse in a way that makes it clear that it is wrong to do that to children, and that is was the adult and not the child who did something wrong, but without demonizing the parent. For example, in the section below the child therapist explains the importance of expressing and mentalizing difficult emotions (angriness and stress) to others (mother):

You will tell her? I mean of course it is for you to decide if you want to tell her or not, but it seems it will be important to find a way of saying it that mom will understand how it makes you feel. Sometimes when we are really angry, it is difficult to talk and explain things so that the other person can understand.

This technique was principally used by the child therapist (adolescent therapist, 2/15, and child therapist, 5/13). The coded frequency was low in all therapy sessions (adolescent therapist, $0.9 \%$, and child therapist, $1.6 \%$ ). 
Muñoz Specht et al.

\section{Main mentalizing techniques}

The second category of the coding tree includes four essential mentalization-based interventions used by the therapists with the aim of directly stimulating the mentalization capacity of the patient during the therapy sessions. Five subcategories emerged from this coding process.

Figure 3 illustrates the second conceptual framework section with all mentalization-based techniques that were organized under the "basic mentalizing techniques" theme.

Exploring mental states. This is one of the fundamental techniques used with the aim of enhancing mentalization directly and is centered on the therapist's capacity to continually question internal mental states in order to understand the immediate reality. This questioning stance may concern both the patient and the therapist. Allen et al. (2008) emphasize the importance of using curiosity and adopting a "not knowing attitude" toward the thoughts and emotions of the patient, and a nonjudgmental curiosity and an attempt to activate a similar interest in the patient toward his or her mental states and motivations. The exploring mental state technique was used by both therapists in relation to self, others, and relationships. The self-category refers to interventions where the therapist inquires about the patient's mental state or mind. The others-category refers to interventions where the therapist aims to promote the capacity of the patient to understand others in term of mental states. Finally, the relationship-category makes reference to interventions where the therapist supports the patient to think about how people and their mental states have impacts on the other. The self-category was used by both therapists in almost all sessions (adolescent therapist, 13/15, and child therapist, 12/13) and was used frequently by both therapists $(11.8 \%$ child therapist, $14.8 \%$ adolescent therapist). Here is one of the several passages where the adolescent therapist adopts a "not knowing attitude" toward the thoughts and emotions of the teenager, explores his mental state, and aims to stimulate the patient's curiosity:

Therapist: This is surprising-you are not proud of yourself even when you have generally good grades? [Said with a quizzical and 
Psychotherapy from a mentalization perspective

playful tone] So I am curious. How does that work? You were expecting more?...

Adolescent: Sometimes yes....

Therapist: Why? Because you worked hard? ....

Adolescent: Yeah ....

Therapist: Yes. Okay. So in that sense, you are disappointed?

Some interventions used by the therapists focused on making the child and adolescent recognize a lack of coherence in the mentalization process of the adolescent (incoherence explaining and describing his and others' mental states). For example, this can be observed when the patient changes his opinion completely toward an event without any apparent reason, or presents contradictory explanations, accounts, goals, or desires without appearing to be aware of the contradiction. When this happens, the therapist can point out this lack of self-coherence by highlighting the opposite points of view that the patient has exposed. To illustrate this technique, the section below shows how the child therapist raises awareness of a lack of self-coherence by highlighting how the child is reacting in opposite ways toward a similar situation (lending toys):

Therapist: I am surprised because sometimes you put a big sticker on your door, which says "if you touch, I am going to kill you," and other times, you are ready to share everything....

Child: Well, yes....

Therapist: Sometimes, you protect a lot, a lot, a lot, and sometimes you don't protect at all and you are ready to share even your most precious things. That's why it took me by surprise a little bit....

This type of intervention was an emergent subcategory and was observed only in the child therapy sessions (3/13). The code frequency was very low in all therapy sessions $(0.5 \%)$.

In some sessions, the therapists can also use their own experiences as a model to help the child or adolescent to mentalize. At the simplest level, the therapists may express their own 
Muñoz Specht et al.

emotional response to something to help the patients recognize the feeling too. This type of intervention was principally used by the adolescent therapist (adolescent therapist, 3/15, vs. child therapist, 1/13). The code frequency was $0.9 \%$ for the adolescent therapist and $0.2 \%$ for the child therapist.

Mentalizing trauma. This intervention is used to help the children put the traumatic experience (which may otherwise remain stored predominantly only as visual and affective memories) into words and help them represent it in words (Ensink \& Normandin, 2011). Given that children need help to mentalize new, upsetting experiences, especially experiences that are so far outside of the norm that basic mentalizing developed in the context of everyday normal life does not apply and is not particularly useful, basic elaboration with the therapist is encouraged so that key elements of the traumatic experience are addressed. This is especially for guilt feelings and feelings of being to blame based on the children's erroneous beliefs that they caused or deserved the accident or abuse, or an unrealistic sense of responsibility and feelings that they should have been able to do something to help the person or could have done something to avoid the event. Often an element of psychoeducation is also used in elaborating the trauma because children may feel that their reactions are bizarre or that they are the only one who reacts in that way or blame themselves unrealistically for abuse. This is an active technique, in which the therapist asks several questions with the aim of helping the child and adolescent to develop a coherent narrative of the traumatic experience and avoid potential confusions and attribution of responsibility to the self (Ensink \& Normandin 2011). In the following example, the child therapist supports the child to mentalize the trauma by helping him put the traumatic experience into words and address possible feelings of responsibility:

Therapist: Someone had a heart attack and was taken away by the ambulance? [talking about a play character]

Child: Yes, that happened to my father, I don't quite know how it happened.

Therapist: Ob yes? 
Psychotherapy from a mentalization perspective

Child: Do you want me to show you?

Therapist: Yes, and maybe show me and tell me a little what happened so that I can understand.

Child: Okay ... I will show you and make the movement. It is like that and then you die [child acts like someone who falls down and clutches his chest, gasps for breath, and then stops moving] Yes, right in front of me.... I said to the police, "No, it wasn't my fault, be fell like that by himself."

Therapist: So you knew it wasn't your fault... I imagine that you probably felt quite confused ... and scared.... seeing your father fall down and not moving. Perhaps not knowing what to do? And then the police coming?

Child: Yes, I did not even know the telephone number ... I dialed perhaps 639.... Me, I wanted to dial 911, but I dialed 639.

Therapist: So you tried your very best to call for help, but you could not, you did not know the number, because you were only ... how old at the time?...

Child: I was very young... I was 4 years old.... I was too young.

Therapist: Yes, you tried your best even though you were so little. I understand. And then the police did come and you said that your father fell like that himself; what do you mean by himself?

Child: That it was not my fault.

Therapist: How could it have been your fault?

Child: It was not my fault.

Therapist: I understand and of course it was not your fault... But did you notice how quick you are to make sure that they did not think that it was your fault? And how quickly you responded again now that it was not your fault...? Nearly as if a part of you is still worried, even though you know it was not your fault.

This technique was observed in one of the child therapy sessions and the code frequency was $0.5 \%$. 
Muñoz Specht et al.

Elaboration technique. This intervention was generally used after the therapist has explored and clarified the patient's difficulties. The therapist may help the patient by reflecting on how the therapist imagines that someone might feel who is in the particular situation the patient describes, but without telling the patient what he or she is feeling. Careful elaboration makes it possible to uncover deeper feelings that may not be apparent; for example, the adolescent or child may appear angry, but underlying this there may be a sense of guilt, humiliation, or failure (Fonagy et al., 2014). The following example shows how the child therapist elaborates a difficult experience (a fight) and attempts to focus on the child's affects:

Therapist: And he laughed at you....

Child: And he was with his little gang. I wasn't even scared of his little gang....

Therapist: You mean that when there are people that make comments that bother you, it makes you want to punch them and sometimes you do it....

Child: Yeah... There's nothing that can stop me from doing it.

Therapist: So when he laughed at you and perhaps you felt a bit ... humiliated ... and you kind of wanted to show him you were not afraid of him?

This type of intervention was used in the majority of child therapy sessions (10/13) and was also used by the adolescent therapist (4/15). The coded frequency was relatively low for both therapists (adolescent therapist, 3.8\%, and child therapist, $4.6 \%)$.

Mentalizing the transference technique. When mentalizing the transference, the aim is to gradually mentalize the therapeutic relationship between patient and therapist as the therapist reflects with the patient on the here-and-now interaction between them (Fonagy et al., 2014). The therapist supports the patient to think about how each affects the other, how their different perspectives are affected by their interactions and by their thoughts about the other's mind, feelings, or thoughts. 
Psychotherapy from a mentalization perspective

In the example below, the adolescent therapist uses a "not knowing attitude" to explore how the teenager perceives her as therapist and what kind of relationship he thinks they may have:

Adolescent: Personally, I don't think that you are here to scold me....

Therapist: Oh well. It has changed a bit since last week...? [Therapist says this with a smile and slightly playful tone to indicate that she is inviting a more playful reflection]

Adolescent: Last week, it's not really that I thought that you were going to scold me... it's like....

Therapist: That I was like a schoolteacher, a school principal...?

Adolescent: Ob yes, a school principal. Now, I would see you as a principal.

Therapist: Now... today, I am a school principal?

Both therapists used this technique in almost all sessions (adolescent therapist, 15/15, and child therapist, 11/13). The code frequency for the adolescent therapist was $18.2 \%$ and for the child therapist was $4.1 \%$.

Transference tracer comments were also used quite frequently, especially by the adolescent therapist (adolescent therapist, $7 / 15$, and child therapist, $1 / 13$ ), and the code frequency for the adolescent therapist was $3.8 \%$ and for the child therapist was $0.2 \%$. These comments are in general followed by, or used in conjunction with, mentalizing the transference interventions to address the patient-therapist relationship issues. This technique is generally used early in the therapy session to highlight patterns of relating (or not relating) to the therapist that the child or adolescent presents, but without overheating it (Fonagy et al., 2014). For example, the adolescent therapist in the section below highlights a strategy of avoidance used by the teenager by gently drawing the adolescent's attention to the way he tends to do something rather than be disturbed by trying to relate: 
Muñoz Specht et al.

Adolescent: Do you have Skype? [Pointing to the therapist's laptop that she uses to record the sessions]....

Therapist: If it starts again, we will put ourselves offline [talking about the computer program Skype, which seems to be activated]

Adolescent: When I type, I try to make the Skype thing go up ... make it explode.

Therapist: It's still interesting to see how ... you use many strategies to avoid being disturbed ... by me.

Adolescent: No, it's not a strategy...

Therapist: Sometimes it's playing with balls, other times, it's playing...

Adolescent: Other times it's Skype....

Therapist: Other times it's Skype....

Adolescent: Other times it's sleeping.

Therapist: Have you ... you notice that?

Adolescent: Well ... yeah.

Interpretative mentalizing technique. The aim of the interpretative mentalizing technique is to increase the mentalization capacity of the young person by stimulating exploration of alternative perspectives, either in relation to the self, the others, or the relationships. After exploring and clarifying the patient's point of view, the therapist may proceed to use this technique by proposing an alternative perspective to consider (Fonagy et al., 2014). In the following example, the adolescent therapist challenges the patient's point of view (about a fight) by proposing an alternative one (you hit him to protect yourself):

Therapist: And do you want to know? Afterwards, I think ... I understood that the famous incident where you hit someone ... the serious ... big case ... I asked myself the question, if there was a 
Psychotherapy from a mentalization perspective

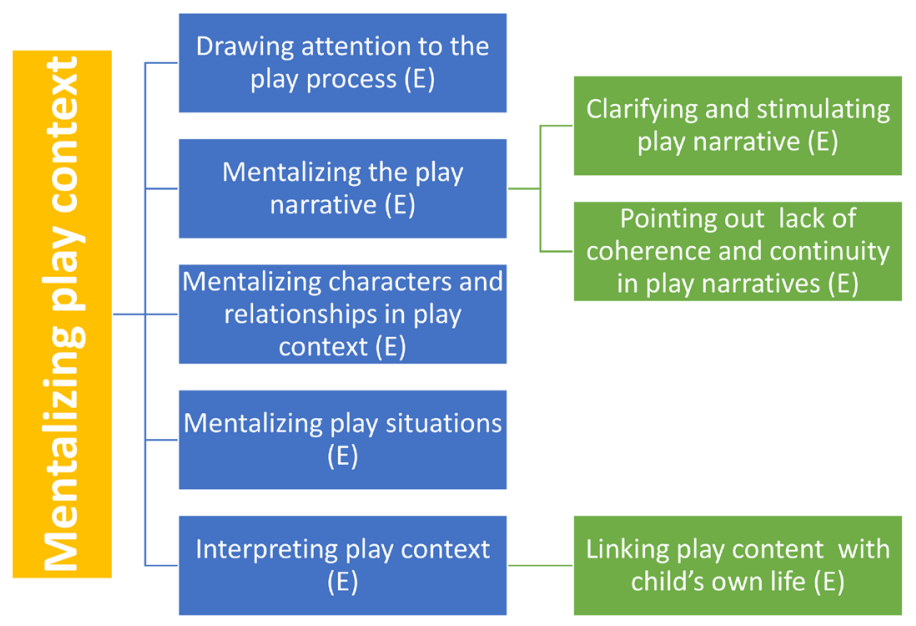

Figure 4. Section 3 of the conceptual framework: mentalizing the play context.

link between the two ... you know between the fact that this person had probably provoked you by humiliating you and the only way you found at that moment, to stop the torture, was hitting him... .

This technique was used by both therapists in almost all sessions (adolescent therapist, 10/15, and child therapist, 10/13). However, the code frequency for the adolescent therapist was higher $(12.3 \%)$ than for the child therapist $(4.7 \%)$.

\section{Mentalizing the play context}

This is the third category of the coding tree, and all mentalization-based interventions used in the play context by the child therapist were organized under this theme. All the interventions described below have the aim of enhancing the child's awareness of mental states in themselves and in others by using play therapy techniques. Five main categories and three subcategories emerged from the coding process. 
Muñoz Specht et al.

Figure 4 illustrates the second conceptual framework section with all mentalization-based techniques (categories) that were organized under the mentalizing the play context theme.

Drawing attention to the play process. The objective of this technique is to draw the child's attention to the way he or she plays during the therapy sessions. This technique is used when the therapist notices a pattern of reacting or playing that is particularly relevant from a clinical point of view. For example, it may be particularly relevant to draw attention to dissociative reactions that the child may otherwise never have the opportunity to be aware of, or trauma-related sexualized behaviors that may put the child in danger outside the therapy context, or trauma-related hypervigilance to noises outside the therapy room that disrupts the child's play and makes it difficult for the child to sustain engagement in play and developing play narratives. This technique is an active process used to highlight potentially problematic areas and/or help to mentalize about the child's type of play.

For example, in the section below the child therapist highlights the child's need of being meticulous by describing his way of preparing the play scenario. The therapist is struck by the contrast between this careful preparation and the otherwise dysregulated behavior of the child, and wants to draw the child's attention in this case to the evidence that he has this "resource," because generally only his negative dysregulated behaviors are focused on. Although the therapist also suspects that there is something about the attention to detail that suggests that the child is overly careful and controlled and inhibits himself from spontaneously expressing himself, she decides to focus on the positive side of this behavior at this point:

Therapist: When you prepare the room ... I noticed that you were very focused, right? ... You were very careful, you made sure that things were done properly and you corrected many small details... Is it only here that you spend a lot of time taking care of things to make sure that everything is nice? Have you noticed that you are actually able to concentrate and take care of things and organize things carefully ... I have the impression that you have this side of 
Psychotherapy from a mentalization perspective

you that is well organized that we see here, but it gets neglected and is hidden by the side that gets into trouble....

This technique was used by the child therapist in a few sessions (3/13). The code frequency was relatively low $(1.3 \%)$.

Mentalizing the play narrative. The basis of this technique is to explore the themes and stories children present in play therapy and facilitate an exchange of ideas and thoughts about these stories. This means that the relationship between child and therapist is one of co-construction, sharing ideas and listening to each other to explore and understand the story that best supports the child in what he or she wants to say. By using this technique, therapist is stimulating the emergence of the child's sense of internal coherence and self-organization. Furthermore, two types of mentalizing the play narrative interventions were identified, namely, clarifying and stimulating play and drawing attention on the lack of coherence and continuity.

In clarifying and stimulating play narrative interventions, the therapist asks questions with the aim of stimulating and elaborating the meaning of the story the child is narrating during the play. This technique is the first step to understanding the play content that the child is presenting during the session and helps the therapist to make sense of what is going on. Additionally, this technique helps and encourages the child to elaborate the stories that he or she is presenting. In the following example, the child therapist explores and stimulates the child's story through questions about one play character:

Therapist: Oh! You say that you've known him as a criminal for a long time? It's not the first time you arrest him?

Child: No ... not the first time, but now it is going to be the last, last time....

Therapist: It is going to be the last time? Why might that be?

Child: It's as if it was the first and the last time that he stays in prison. Until his death....

Therapist: Until his death? 
Muñoz Specht et al.

Child: Unless he makes big progress, but it would surprise me. To date, none of them have managed to get out of jail....

Therapist: Ob yes? He is worried about whether he can make progress and get out of jail ... if there is hope? What could help him to make progress? Is there anyone there that can lend him a hand ... help him a bit or is he all alone?

This technique was used by the child therapist in almost all sessions $(12 / 13)$ and the code frequency was $22.7 \%$.

Therapists may also decide to draw attention to an apparent lack of coherence and continuity in the story enacted in the play of the child, and request clarification when they feel the child can benefit from becoming more aware of this incongruence. This may be used judiciously to bring more awareness around a theme that is central for the child and that the child struggles with. The therapist may gently nudge the child to elaborate further to make the story more coherent. In the section below, the therapist helps the child to further elaborate the story and invites the child to make it more consistent by drawing the child's attention to the apparent lack of continuity in the story enacted in the play:

Therapist: Ah, the race took place? ...

Child: It is over....

Therapist: The race is finished? ....

Child: Yeah....

Therapist: Ob yes? What happened during the race? That was quick hub? I didn't have the time to see, I think. I didn't understand that it was a race. What happened?

Child: Now it's over....

Therapist: Okay ... What happened before it ended?

Child: Now there is a highway....

Therapist: Okay, now it is highway ... but the race, what happened? I was wondering if there was a winner? 
Psychotherapy from a mentalization perspective

Child: No ... no winner.

Therapist: Ah, so ... now ... does it mean that Bigfoot [the main play character] is without a race stadium? How does he feel about that? His stadium has been replaced by a highway?

This technique was used by the child therapist in a few sessions $(3 / 13)$ and the code frequency was $0.5 \%$.

Mentalizing characters and relationships in the play context. The aim of this technique is to stimulate the mentalization capacity of the child by helping him or her think in terms of mental states of the play characters and their relationships. In this way, the child and the therapist elaborate a mentalizing process together during the play sessions. The therapist continually constructs and reconstructs an image of the characters of the child's play in his or her mind to help the child to think in terms of mental states, by asking what and why the characters feel, think, or behave in a particular way during the play. Moreover, the therapist supports the child to think about the relationships between characters, for example, by asking about the impact of the behavior of the characters on the others. In the section below, the child therapist explores the character's mental states and his relationships by questioning the reasons the monster is angry and by trying to understand the reason he becomes aggressive:

Child: Now, because of him, he is a bit mad [makes the dinosaurs fight $]. . .$.

Therapist: Ah, he did not calm down, but you know, he did not do anything in the end....

Child: I know....

Therapist: People called him a monster, but it does not seem like he did anything wrong?

Child: No ... but he never stops making grr, grr, grr (He makes threatening gestures and angry noises). 
Muñoz Specht et al.

Therapist: What does he do? ...

Child: Grr, grr grr, he jumps on it....

Therapist: Ah. Why did he do that? ...

Child: I don't know. It's a monster. You are dead [referring to the dinosaur]....

Therapist: Yeah, yeah ... maybe even monsters have good reasons to do things, but he [dinosaur]... We don't even ask him why?

This technique was used by the child therapist in almost all sessions (12/13) and was the second most frequently used intervention she used. The code frequency was $12.7 \%$.

Mentalizing play situations. The aim of this technique is to draw the child's attention to the themes he or she chose during the play sessions. This technique is used when the therapist realizes that the child's play themes are particularly relevant from a clinical point of view. This technique is an active process where the therapist summarizes the main theme expressed in the play in mental state terms. For example, in the section below the therapist summarizes the theme of fear of being punished and put in a place that is dangerous and frightening when one does something wrong, a theme that is subjectively salient for the boy as social services are considering a placement in a type of youth detention center:

Therapist: I also learned that we are better off not ending up in jail because it's dangerous. So then it's a bit frightening this idea of doing something wrong, because ... if we do, we end up in jail... .

This technique was used by the child therapist in 3/13 sessions and the code frequency was relatively low $(1.1 \%)$.

Interpreting play context. This technique is used when the therapist is reasonably clear about the play content and is confident to infer what the child may have in mind during the play, based on the child's behavior, emotional state, play content (e.g., characters, play scenarios, conflicts between characters), and the therapist's clinical knowledge. This technique has to be 
Psychotherapy from a mentalization perspective

used with caution, adopting a "wondering" approach so that the child does not feel dismissed or forced to accept the therapist's point of view. For instance, in the section below the child therapist, in a very gentle and cautious way, suggests an alternative point of view for understanding the motivation of the play character.

Therapist: ...It seems like that the city's big millionaire is a guy who makes a lot of effort so that people love him.... Maybe a bit like, everybody wants people to love them, eh?...

Child: Bzzzzzt. Bvuuut [car noise] ... Yeah....

Therapist: Yeah. Except that, there are people who are sure that others love them and there are people who are really afraid that others don't love them.... The city's millionaire, I was wondering if we could say that he ... he's someone who really wants people to admire him and to love him .... Because sometimes, maybe he has doubts...?

Child: Hmbm....

This technique was used by the child therapist in the majority of sessions (9/13), but the overall coded frequency was relatively low $(2.8 \%)$.

On some occasions, therapists used a technique that can be described as linking the play content with the child's own life. This was only used when the therapist had a strong therapeutic alliance and a good understanding of the child's difficulties. It is used cautiously, considering that a core principle of play therapy is to stay within the medium of play when this is available. This intervention was sometimes used after the intervention interpreting the play context, when it is deemed important to explicitly address something happening in the child's life and where the stakes are sufficiently high to justify this. In the following example, the child therapist links what is happening in the play with the way the child reacts in real life to help the child understand his reactions:

Child: Eee, he's a man. He's not a child... [They are talking about "the city millionaire"] 
Muñoz Specht et al.

Therapist: Oh!... but it seems like he feels very hurt and a little angry and that makes him hurt other people, when ... generally, not all the time, it's because they are afraid ... If I understand well, the game that you play, is it a bit similar to what you do too? ...

Child: A bit...

Therapist: Perhaps sometimes you are hurt, afraid, or angry and want to hurt, but at other moments, you're also a boy who wants to do great things, who can be generous, and who can also be calm. Might that be the way it is for you? ...

Child: We can say that, yes....

This technique was used by the child therapist in some sessions only $(4 / 13)$, and the coded frequency was low $(1 \%)$.

\section{Discussion}

The aim of this exploratory study was to identify, categorize, and conceptualize mentalization-based interventions in the context of psychodynamic psychotherapy with children and adolescents, and then to organize this into a coherent framework. In total, 24 techniques were identified in the sessions that were coded. In addition to the seven well-known MBT techniques described in key texts on MBT, 17 additional techniques emerged from the coding process. In terms of a coherent framework for organizing and conceptualizing mentalization-based techniques, all the interventions could be considered to reflect a mentalizing stance. This was then divided into three categories of intervention: (1) supporting mentalization stance interventions, (2) the basic mentalizing techniques, and (3) the mentalizing the play context.

The findings indicate that both therapists used an extensive range of mentalization-based interventions in all their therapy sessions. In addition to what has been described in the previous literature, which has mostly focused on MBT with adults, 17 MBT techniques used in therapy with children and youth were identified during the coding process. Both therapists frequently used interventions aimed at exploring and clarifying affective dimensions, behaviors, and interpersonal reactions in the context 
Psychotherapy from a mentalization perspective

of the everyday lives of the young patients. The clarification and exploration technique may superficially appear to be a simple exploration of the child or adolescent's experience, but it likely has a central function in helping patients clarify and elaborate their central difficulties by encouraging them to continue talking about difficult feelings, thoughts, interactions, and reactions that may be troubling or dangerous. Additionally, the clarification and exploration techniques are also essential for the therapist to elaborate a nuanced understanding of the patient and the exact nature of the problem. This may be particularly useful where patients do not themselves know what the problem is or how to put it into words, and it helps to give the therapist and the patient a clearer picture of exactly what the problem is and the actual behavior and emotional reactions that the patient may be struggling with. Exploration and clarification appears to be a widely used technique, and appears to be central in the process through which the patient and therapist develop a mentalizing process together and co-construct an understanding of the problem (Fonagy et al., 2014).

A further finding of this study was the "mentalizing trauma" category that emerged from the coding process. This technique was used on specific occasions by the child therapist to help the child put into words feelings and reactions regarding an important trauma experienced by the child in order to arrive at a more adequate account of the traumatic experience and where trauma-related impacts, including guilt feelings and mistrust, are put into words and addressed. Mentalization regarding trauma appears to be particularly important for the adaptive functioning of individuals who have experienced childhood abuse and neglect, especially when trauma-related affects such as aggression and fear are activated (Berthelot et al., 2015; Ensink et al., 2015) and is a key component of effective treatments, for example, with sexually abused children (Cohen, Deblinger, Mannarino, \& Steer, 2004, Ensink \& Normandin, 2012). Children who have faced traumatic experiences likely require additional help to develop a narrative about the trauma that can facilitate the realistic representation of these difficult experiences and their impact on the child (Allen, 2012; Fonagy et al., 2002; Shipman \& Zeman, 2001). 
Muñoz Specht et al.

An important finding of this pilot study was the identification and elaboration of mentalization-based interventions used in play therapy. The child therapist used an extensive range of mentalization-based interventions, including eight different techniques aimed at enhancing the child's mentalization capacities through play. Thinking about play therapy from a mentalization perspective appears particularly promising, and play therapy may be especially important for facilitating the development of mentalizing in children. Play is theorized by Target and Fonagy (1996) to be a precursor of mentalizing, and there is preliminary evidence to support this (Tessier et al., 2016). The categories identified in this study are generally in line with previous observations that the play therapist works with the mental content inferred from the child's play and behavior (Bleiberg, Fonagy, \& Target, 1997; Ensink \& Normandin, 2012; Fonagy, 2000; Goodman et al., 2016; Zevalkink et al., 2012).

One preestablished category, the "stop, rewind, and explore" category was not observed in any of the therapy sessions coded for the study. Fonagy et al. (2014) describe this technique as a strategy that the therapist uses when, for example, adults or adolescents with borderline personality disorders lose control during the session and become nonmentalizing, with the therapist helping the patient to rewind to the point where mentalization was lost to help the patient explore and think about what happened. This technique may be specific to dealing with affect storms after interventions by the therapist, and it was likely not observed in this study because the patients did not present with this type of difficulty or it was not part of the repertoire of techniques used by the two therapists who participated in this study.

While the study methodology enabled us to confirm the use of previously identified MBT techniques and also identify additional techniques addressing mentalization that may be especially relevant to working with children and young people, an evident limitation of the study is that the therapy sessions of only two therapists were examined. Both therapists considered that a mentalization-based framework was implicit in their work, and they also identified themselves as psychodynamic therapists, so that the interventions identified may not be representative of the full range of mentalization interventions used by therapists with other training. Further research is thus needed to identify 
Psychotherapy from a mentalization perspective

a comprehensive range of interventions used by MBT therapists with other clinical backgrounds. Furthermore, the type of disorder or presenting difficulties of the child and youth may also have had an impact on the interventions used by the therapists. Further research is needed, first to establish whether stimulating mentalization is central to a range of child and adolescent therapies, and then to evaluate whether such techniques are at the core of effective approaches. Finally, while the focus of this study was to identify mentalizing techniques, further work may also be necessary to examine whether there are techniques that cannot be adequately conceptualized in terms of mentalizing, and whether such techniques may contribute to therapeutic change through other pathways.

In sum, a wide range of mentalization-based techniques were identified using a single-case naturalistic research methodology, indicating that this type of approach holds promise for increasing our understanding of what experienced child and adolescent therapists do, with mentalization used as a unifying conceptual framework.

\section{References}

Allen, J. G. (2012). Mentalizing in the development and treatment of attachment trauma. London, UK: Karnac Books.

Allen, J. G., Fonagy, P., \& Bateman, A. W. (2008). Mentalizing in clinical practice. Washington, DC: American Psychiatric Publishing.

Bateman, A. W., \& Fonagy, P. (Eds.). (2012). Handbook of mentalizing in mental health practice. Arlington, VA: American Psychiatric Publishing.

-Berthelot, N., Ensink, K., Bernazzani, O., Normandin, L., Luyten, P., \& Fonagy, P. (2015). Intergenerational transmission of attachment in abused and neglected mothers: The role of trauma-specific reflective functioning. Infant Mental Health Journal, 36, 200-212. doi:10.1002/imhj.21499

Bleiberg, E., Fonagy, P., \& Target, M. (1997). Child psychoanalysis: Critical overview and a proposed reconsideration. Child and Adolescent Psychiatric Clinics of North America, 6, 1-38.

-Clarkin, J. F., Levy, K. N., Lenzenweger, M. F., \& Kernberg, O. F. (2007). Evaluating three treatments for borderline personality 
Muñoz Specht et al.

disorder: A multiwave study. American Journal of Psychiatry, 164, 922-928. doi:10.1176/ajp.2007.164.6.922

-Cohen, J. A., Deblinger, E., Mannarino, A. P., \& Steer, R. (2004). A multi-site, randomized controlled trial for children with abuserelated PTSD symptoms. Journal of the American Academy of Child and Adolescent Psychiatry, 43, 393-402. doi:10.1097/00004583200404000-00005.

Ensink, K., Bégin, M., Normandin, L., \& Fonagy, P. (2016). Maternal and child reflective functioning in the context of child sexual abuse: Pathways to depression and externalising difficulties. European Journal of Psychotraumatology, 7, article 30611. doi:10.3402/ejpt. v7.30611

Ensink, K., \& Normandin, L. (2011). Le traitement basé sur la mentalisation chez les enfants agressés sexuellement et leurs parents [Mentalization-based therapy for sexually abused children and their parents]. In M. Hébert, M. Cyr, \& M. Tourigny (Éds.), L'agression sexuelle envers les enfants, Tome I [Sexual abuse of children, Volume I] (pp. 399-440). Québec, Canada: Presses de 1 Université du Québec.

Ensink, K., Normandin, L., Target, M., Fonagy, P., Sabourin, S., \& Berthelot, N. (2015). Mentalization in children and mothers in the context of trauma: An initial study of the validity of the Child Reflective Functioning Scale. British Journal of Developmental Psychology, 33, 203-217. doi:10.1111/bjdp.12074

Fonagy, P. (2000). Mentalization and personality disorder in children: A current perspective from the Anna Freud Centre. In T. Lubbe (Ed.), The borderline psychotic child (pp. 69-89). London, UK: Routledge.

Fonagy, P., Gergely, G., Jurist E. L., \& Target, M. (2002). Affect regulation, mentalization, and the development of the self. New York, NY: Other Press.

Fonagy, P., Rossouw, T., Sharp, C., Bateman, A., Allison, L., \& Farrar, C. (2014). Mentalization-based treatment for adolescents with borderline traits. In C. Sharp \& J. L. Tackett (Eds.), Handbook of borderline personality disorder in children and adolescents (pp. 313332). NewYork, NY: Springer. doi:10.1007/978-1-4939-0591-1_21

Fonagy, P., Steele, M., Steele, H., Moran, G. S., \& Higgitt, A. C. (1991). The capacity for understanding mental states: The reflective self in parent and child and its significance for security of attachment. Infant Mental Health Journal, 12, 201-218. doi:10.1002/10970355(199123)12:3<201::AID-IMHJ2280120307>3.0.CO;2-7

-Fonagy, P., \& Target, M. (1996). Playing with reality: I. Theory of mind and the normal development of psychic reality. International Journal of Psychoanalysis, 77, 217-233.

Fonagy, P., \& Target, M. (2000). Playing with reality: III. The persistence of dual psychic reality in borderline patients. International Journal of Psychoanalysis, 81, 853-873.

-Goodman, G., Midgley, N., \& Schneider, C. (2016). Expert clinicians' prototypes of an ideal child treatment in psychodynamic and cogni- 
Psychotherapy from a mentalization perspective

tive-behavioral therapy: Is mentalization seen as a common process factor? Psychotherapy Research, 26, 590-601. doi:10.1080/1050330 7.2015.1049672

-Goodman, G., Reed, P., \& Athey-Lloyd, L. (2015). Mentalization and play therapy processes between two therapists and a child with Asperger's disorder. International Journal of Play Therapy, 24, 13-29. doi:10.1037/a0038660

-Hankin, B. L., Wetter, E., Cheely, C., \& Oppenheimer, C. W. (2008). Beck's cognitive theory of depression in adolescence: Specific prediction of depressive symptoms and reciprocal influences in a multi-wave prospective study. International Journal of Cognitive Therapy, 1, 313-332. doi:10.1521/ijct.2008.1.4.313

Ingley-Cook, G., \& Dobel-Ober, D. (2013). Innovations in practice: Group work with children who are in care or who are adopted:

Lessons learnt. Child and Adolescent Mental Health, 18, 251-254. doi:10.1111/j.1475-3588.2012.00683.x

Kernberg, P. F., \& Chazan, S. E. (1991). Children with conduct disorders: A psychotherapy manual. New York, NY: Basic Books.

Kernberg, P. F., Weiner, A. S., \& Bardenstein, K. (2000). Personality disorders in children and adolescents. New York, NY: Basic Books.

-Laurenssen, E. M., Hutsebaut, J., Feenstra, D. J., Bales, D. L., Noom, M. J., Busschbach, J. J., ... Luyten, P. (2014). Feasibility of mentalizationbased treatment for adolescents with borderline symptoms: A pilot study. Psychotherapy, 51, 159-166. doi:10.1037/a0033513

Lindqvist, K. (2013, April). Mentalization based time-limited psychotherapy with children and parents. Workshop at the Erica Foundation, Stockholm, Sweden. Workshop document retrieved from http://www. ericastiftelsen.se/for/publ/Workshop_Erica_Foundation_April_2013. pdf

Midgley, N. (2012). Reading Anna Freud. New York, NY: Routledge.

Midgley, N., \& Vrouva, I. (Eds.). (2013). Minding the child: Mentalization-based interventions with children, young people and their families. New York, NY: Routledge.

Miles, M. B., \& Huberman, A. M. (1994). Qualitative data analysis: An expanded sourcebook. Thousand Oaks, CA: Sage.

Normandin, L., Ensink, K., Yeomans, F. E., \& Kernberg, O. F. (2014). Transference-focused psychotherapy for personality disorders in adolescence. In C. Sharp \& J. L. Tackett (Eds.), Handbook of borderline personality disorder in children and adolescents (pp. 333-359). New York, NY: Springer. doi:10.1007/978-1-4939-0591-1_22

Pope, C., Ziebland, S., \& Mays, N. (2000). Analysing qualitative data. $B M J, 320,114-116$. doi:10.1136/bmj.320.7227.114

-Ramires, V. R. R., Schwan, S. \& Midgley, N. (2012). Mentalizationbased therapy with maltreated children living in shelters in southern Brazil: A single case study. Psychoanalytic Psychotherapy, 26, 308-326. doi:10.1080/02668734.2012.730546 
Muñoz Specht et al.

Reyna, V. F., Chapman, S. B., Dougherty, M. R., \& Confrey, J. E. (Eds.). (2012). The adolescent brain: Learning, reasoning, and decision making. Washington, DC: American Psychological Association. doi:10.1037/13493-000

Ritchie, J., \& Spencer, L. (2002). Qualitative data analysis for applied policy research. In A. M. Huberman \& M. B. Miles (Eds.), The qualitative researcher's companion (pp. 305-329). Thousand Oaks, CA: Sage.

-Rossouw, T. I., \& Fonagy, P. (2012). Mentalization-based treatment for self-harm in adolescents: A randomized controlled trial. Journal of the American Academy of Child \& Adolescent Psychiatry, 51, 13041313. doi:10.1016/j.jaac.2012.09.018

-Sharp, C., Croudace, T. J., \& Goodyer, I. M. (2007). Biased mentalizing in children aged seven to 11: Latent class confirmation of response styles to social scenarios and associations with psychopathology. Social Development, 16, 181-202. doi:10.1111/j.14679507.2007.00378.x

-Shipman, K. L., \& Zeman, J. (2001). Socialization of children's emotion regulation in mother-child dyads: A developmental psychopathology perspective. Development and Psychopathology, 13, 317-336. doi:10.1017/S0954579401002073

- Southam-Gerow, M. A., \& Kendall, P. C. (2000). A preliminary study of the emotion understanding of youths referred for treatment of anxiety disorders. Journal of Clinical Child Psychology, 29, 319-327. doi:10. 1080/14616734.2010.501988

-Steinberg, L. (2008). A social neuroscience perspective on adolescent risk-taking. Developmental Review, 28, 78-106. doi:10.1016/j. dr.2007.08.002

-Suchman, N. E., DeCoste, C., Leigh, D., \& Borelli, J. (2010). Reflective functioning in mothers with drug use disorders: Implications for dyadic interactions with infants and toddlers. Attachment \& Human Development, 12, 567-585. doi:10.1080/14616734.2010.501988

- Target, M., \& Fonagy, P. (1996). Playing with reality: II. The development of psychic reality from a theoretical perspective. International Journal of Psycho-Analysis, 77, 459-479.

- Taubner, S., \& Curth, C. (2013). Mentalization mediates the relation between early traumatic experiences and aggressive behavior in adolescence. Psibologija, 46, 177-192. doi:10.2298/PSI1302177T

-Terradas, M. M., \& Achim, J. (2013). Arrête de faire semblant, on joue pour vrai! Intégration de techniques d'intervention basées sur la mentalisation à la psychothérapie d'enfants d'orientation psychanalytique ["Stop pretending, we are playing for real!" Integration of mentalization-based techniques in psychoanalytically oriented child psychotherapy]. La Psychiatrie de L'enfant, 56, 439-465. doi:10.3917/ psye.562.0439 
Psychotherapy from a mentalization perspective

Tessier, V. P., Normandin, L., Ensink, K., \& Fonagy, P. (2016). Fact or fiction? A longitudinal study of play and the development of reflective functioning. Bulletin of the Menninger Clinic, 80, 60-79.

-Thomas, D. R. (2006). A general inductive approach for analyzing qualitative evaluation data. American Journal of Evaluation, 27, 237-246. doi:10.1177/1098214005283748

Verheugt-Pleiter, J. \& Zevalkink, J. (2008). Mentalizing in child therapy: Guidelines for clinical practitioners. London, UK: Karnac Books.

Wellman, H. M., \& Lagattuta, K. H. (2000). Developing understandings of mind. In S. Baron-Cohen, H. Tager-Flusberg, \& D. Cohen (Eds.), Understanding other minds: Perspectives from developmental cognitive neuroscience (2nd ed., pp. 21-29). Oxford, UK: Oxford University Press.

Zevalkink, K., Verheugt-Pleiter, A., \& Fonagy, P. (2012). Mentalizationinformed child psychoanalytic psychotherapy. In A. Bateman \& P. Fonagy (Eds.), Handbook of mentalizing in mental health practice (pp. 129-158). Washington, DC: American Psychiatric Publishing. 